\section{INFLUENCE OF HAEMATOLOGICAL INDICES ON COMBAT ATHLETIC GROUPS IN NIGERIA}

Venkateshwarlu Kankanala, I Igah J Ameh, ${ }^{2}$ Ezra A Gunen ${ }^{2}{ }^{1}$ Department of Nutrition and Dietetics, Kaduna Polytechnic, Kaduna, Nigeria; ${ }^{2}$ Department of Physical and Health Education, Ahmadu Bello University, Zaria, Nigeria

\subsection{6/bjsm.2010.078725.102}

Alterations in different haematological indices have been shown to affect both health and performance. These alterations seem to be influenced by demographic factors as sex and age. However, the influence of sex on the haematological indices of judo karate and taekwondo athletic groups has not been established in Nigeria. The purpose of this study was therefore to find out differences among judo, karate and taekwondo athletic groups in their haematological indices and influence of sex on these indices. To achieve the purpose of this study 15 male and 15 female subjects were randomly drawn from each of judo, karate and taekwondo athletic group (45 males and 45 females). They were tested for haemoglobin (HB), haematocrit (HCT), mean corpuscular volume (MCV), mean corpuscular haemoglobin concentration (MCHC), serum ion, total iron binding capacity, percent transferrin saturation, serum ferritin, creatine kinase (CK) and glycosylated haemoglobin status (GHS). The results of this study show that judo groups had higher MCV (86.14 $\pm 0.18 \%)$ and MCHC (28.64 $\pm 0.49 \%)$, while karate group has higher mean serum ion $(115.74 \pm 2.31 \mathrm{mg} / \mathrm{dl})$, whereas the taekwondo group has a higher mean HB $(15.42 \pm 0.37 \mathrm{~g} /$ dl), mean HCT (45.88 $\pm 1.22 \%)$, total ion binding capacity $(366.11 \pm 7.84 \mathrm{mg} / \mathrm{dl})$, serum ferritin $(1.65 \pm 0.05 \mathrm{mg} / \mathrm{dl}), \mathrm{CK}$ $(100.25 \pm 2.86 \mathrm{U})$ and GHS $(5.63 \pm 0.28 \%)$. The results further revealed that male judo group had higher mean values for most of the haematological indices as was the case with male karate and taekwondo athletes. However, female judo group has higher MCV and MCHC while female taekwondo group had higher mean $C K$ values compared with their male counterparts. 